\title{
Biocompatibility of $\alpha-\mathrm{Al}_{2} \mathrm{O}_{3}$ Ceramic Substrates with Human Neural Precursor Cells
}

\author{
Akrivi Asimakopoulou ${ }^{1}, *$, Ioannis Gkekas ${ }^{2}$, Georgia Kastrinaki ${ }^{3}$, Alessandro Prigione ${ }^{4}$, \\ Vasileios T. Zaspalis ${ }^{3,5}$ and Spyros Petrakis ${ }^{2, *}$ (D) \\ 1 Chemical Process \& Energy Resources Institute/Centre for Research and Technology Hellas, \\ 57001 Thessaloniki, Greece \\ 2 Institute of Applied Biosciences/Centre for Research and Technology Hellas, 57001 Thessaloniki, Greece; \\ gkekasioannis@certh.gr \\ 3 Laboratory of Inorganic Materials/Chemical Process \& Energy Resources Institute/Centre for Research and \\ Technology Hellas, 57001 Thessaloniki, Greece; georgiak@certh.gr (G.K.); zaspalis@cperi.certh.gr (V.T.Z.) \\ 4 Department of General Pediatrics, Neonatology and Pediatric Cardiology University Clinic Düsseldorf, \\ Heinrich Heine University, 40225 Düsseldorf, Germany; alessandro.prigione@hhu.de \\ 5 Department of Chemical Engineering, Aristotle University, P.O. Box 1517, 54006 Thessaloniki, Greece \\ * Correspondence: asimak@certh.gr (A.A.); spetrak@certh.gr (S.P.); Tel.: +30-2310-498-245 (A.A.); \\ $+30-2311-257-525$ (S.P.)
}

Received: 27 July 2020; Accepted: 11 September 2020; Published: 16 September 2020

\begin{abstract}
Background: Biocompatible materials-topography could be used for the construction of scaffolds allowing the three-dimensional (3D) organization of human stem cells into functional tissue-like structures with a defined architecture. Methods: Structural characterization of an alumina-based substrate was performed through XRD, Brunauer-Emmett-Teller (BET) analysis, scanning electron microscopy (SEM), and wettability measurements. Biocompatibility of the substrate was assessed by measuring the proliferation and differentiation of human neural precursor stem cells (NPCs). Results: $\alpha-\mathrm{Al}_{2} \mathrm{O}_{3}$ is a ceramic material with crystallite size of $40 \mathrm{~nm}$; its surface consists of aggregates in the range of 8-22 $\mu \mathrm{m}$ which forms a rough surface in the microscale with 1-8 $\mu \mathrm{m}$ cavities. The non-calcined material has a surface area of $5.5 \mathrm{~m}^{2} / \mathrm{gr}$ and pore size distribution of $20 \mathrm{~nm}$, which is eliminated in the calcined structure. Thus, the pore network on the surface and the body of the ceramic becomes more water proof, as indicated by wettability measurements. The alumina-based substrate supported the proliferation of human NPCs and their differentiation into functional neurons. Conclusions: Our work indicates the potential use of alumina for the construction of 3D engineered biosystems utilizing human neurons. Such systems may be useful for diagnostic purposes, drug testing, or biotechnological applications.
\end{abstract}

Keywords: a-alumina; nanoporosity; wettability; protein adsorption; human neural precursor cells; biocompatibility; differentiation; neuron

\section{Introduction}

The nervous system is characterized by high-complexity and three-dimensional (3D) interconnectivity of its cellular components, i.e., the neurons and non-neuronal glial cells. However, in brain disorders (e.g., traumatic brain injury), tissue architecture is damaged and neuronal signals which regulate the homeostasis and function of the body are not properly transmitted. The recent advances in induced-pluripotent stem cell technology and the development of the appropriate differentiation protocols allowed the in vitro generation of human neuronal cells which could be used for biotechnological or regenerative therapeutic approaches. These cells are predominantly grown in two-dimensional (2D) monolayer cultures which are easy to use and analyze. However, tissue-specific 
architecture and mechanical signals that regulate the maturation, communication, and physiological function of neurons are not properly modelled. In contrast, 3D cultures allow the organization of neuronal cells into tissue-like structures that better reproduce the in vivo microenvironment. Neural blocks [1] or cell spheroids have been previously utilized for the construction of complex 3D structures (reviewed in [2]). Although promising, these structures may not be functional in vitro or in vivo, due to insufficient provision of nutrients in cells of their inner layers or limited integration and poor functionality into the host tissue. On the other hand, scaffolds made from biocompatible materials may provide structural support for cell adhesion, proliferation, and differentiation mimicking the cellular microenvironment. A number of scaffolds made from solid [3-5], microfibrous materials [6], or gels [7] have been previously described to support the proliferation and localized differentiation of murine neural stem cells, indicating their potential value for neural tissue regeneration [8]. Among them, 3D foam biomaterials provide efficient cell adhesion, proliferation, and differentiation due to their unique properties (e.g., high surface-to-volume ratio, 3D porous structure) [9]. Such materials may be also used for the construction of engineered biosystems modeling brain compartmentalization that would allow real-time analyses of brain function [10].

Bioceramics (e.g., alumina, zirconia, titania, hydroxyapatite, glass ceramics) are used for implantation, repair, and reconstruction of the diseased or damaged parts of the body [11]. In some cases, they can strongly bond to living tissues, creating a stable interface and triggering a range of biological responses, such as tissue regeneration while degrading over time [12]. In recent years alumina has been preclinically and clinically studied in designing dental and orthopedic biomaterials [13-15] while the controlled network of its porous structure provides advanced functionalities to immunoisolation devices, scaffolds for tissue engineering, biomolecular filtration, and state of the art controlled release drugs [16-18]. The structural characteristics and composition of alumina substrates make them proper scaffolds for cell cultures, based on the optimized surface wettability for cell adhesion and the surface chemical modification with functional groups which may control the differentiation of neural stem cells [19].

The aim of the present work is to test the biocompatibility of an alumina-based ceramic material which could be fabricated in desired shapes and evaluate whether it supports the proliferation and differentiation of human neural precursor cells (NPCs). A thorough characterization of the surface of non-calcined and calcined alumina was first performed, in order to better understand the cell-material interaction. Most importantly, we show that alumina is biocompatible with human NPCs as it supports their proliferation, differentiation, and survival of functional NPC-derived neurons. These results indicate that alumina may be used for the development of scaffolds for neural-like 3D structures.

\section{Materials and Methods}

\subsection{Ceramic Substrate Surface Modification}

Alumina discs (T-ceramics machinable alumina, THERMANSYS ${ }^{\circledR}$ ) of $11 \mathrm{~mm}$ diameter and $4 \mathrm{~mm}$ height (suitable to fit in 12-well insert plate) were selected. After full firing to $1700^{\circ} \mathrm{C}$, a dense material with all mechanical, chemical, and electrical properties of high purity recrystallized alumina was obtained (Table 1). Full firing temperature profile is as follows: temperature increase to $1100{ }^{\circ} \mathrm{C}$ with a heating rate of $4{ }^{\circ} \mathrm{C} / \mathrm{min}$ and then to $1700{ }^{\circ} \mathrm{C}$ with a heating rate of $2{ }^{\circ} \mathrm{C} / \mathrm{min}$, maintaining the temperature at $1700^{\circ} \mathrm{C}$ for $6 \mathrm{~h}$ and cool down the furnace gradually with a rate of $4{ }^{\circ} \mathrm{C} / \mathrm{min}$. A degree of shrinkage of $20-21 \%$ approximately was noticed, resulting in reduced dimensions of the final disc ( $8.8 \mathrm{~mm}$ diameter and $3.2 \mathrm{~mm}$ height) as well in reduced porosity and pore size. Both non-calcined (ncA) and calcined (cA) samples of T-ceramics machinable alumina were structurally characterized via state-of-the-art material surface analysis methods, while only calcined alumina was evaluated as a potential substrate for cell culture. 
Table 1. Properties of T-ceramics machinable alumina, THERMANSYS ${ }^{\circledR}$ [20].

\begin{tabular}{cccc}
\hline Property & Value & Property & Value \\
\hline Max. Operating Temperature, ${ }^{\circ} \mathrm{C}$ & 1750 & Dielectric Strength, AC-KV/mm & 16.9 \\
Porosity, $\%$ vol. & $<0.5$ & Dielectric Constant, $1 \mathrm{MHz}$ & 9.8 \\
Density, gr/cm ${ }^{3}$ & 3.8 & Compressive Strength, $\mathrm{MPa}$. & 2600 \\
Color & Ivory & Flexural Strength, $\mathrm{MPa}$ & 380 \\
Thermal Conductivity at $20{ }^{\circ} \mathrm{C}, \mathrm{W} / \mathrm{mK}$ & 30 & Elastic Modulus, $\mathrm{GPa}$ & 375 \\
Thermal Conductivity at $800{ }^{\circ} \mathrm{C}, \mathrm{W} / \mathrm{mK}$ & 8 & Shear Modulus, $\mathrm{GPa}$ & 152 \\
Coefficient of Thermal Expansion, $10-6 /{ }^{\circ} \mathrm{C}$ & 8.4 & Hardness, $\mathrm{kg} / \mathrm{mm}^{2}$ & 1440 \\
\hline
\end{tabular}

\subsection{XRD Spectroscopy}

The X-Ray diffraction was performed by an XRD D500/501 apparatus (Siemens, Berlin, Germany), equipped with $\mathrm{Cu}$ Ka radiation source from 10-80 $2 \theta$ angle with 0.04 step.

\subsection{Brunauer-Emmett-Teller (BET) Analysis}

Surface porosity, average pore size and pore size distribution were determined for all alumina samples by BET method employing a Micromeritics Tri-Star system at $433 \mathrm{~K}$ and maintained at this temperature for $4 \mathrm{~h}$ under vacuum $(\sim 50 \mathrm{mTorr})$ and degassing at $250{ }^{\circ} \mathrm{C}$.

\subsection{Wettability}

The wetting ability of the ceramic material was measured by the Water Contact Angle method. An in-house contact angle measurement instrument based on a high-resolution sensor camera (Nikon D5600, Tokyo, Japan, AF-P NIKKOR 18-55 mm 1:3.5-5.6 G) was employed according to the arrangement proposed in [21]. After cleaning the surface of the ceramics with acetone, a $50 \mu \mathrm{L}$ double distilled water drop was added manually via a glass Pasteur pipette with opening of $1 \mathrm{~mm}$. Drop images on the surface of each material were taken after 1-2 s. For each material (non-calcined and calcined alumina), three samples were tested and for each sample, three measurements on different locations of their surface were performed. With the use of proper lighting and alignment of the sample/focal point and the camera, photos with no reflection were obtained. The contact point between solid, liquid, and gas phase (i.e., ceramic surface, water drop, and air, respectively) was detected by the intersection between the solid surface line and the drop profile, both detected after digitally zooming the images and processing them properly in a raster graphics editor software.

\subsection{NPC Culture}

NPCs were obtained from healthy human induced pluripotent stem cells (iPSCs) (ethical approval: IRB code \#EA2/131/13), as previously described [22]. Calcined $\mathrm{Al}_{2} \mathrm{O}_{3}$ ceramic discs were coated with Matrigel (BD Biosciences). NPCs were seeded on discs $\left(0.25 \times 10^{6} \mathrm{cells} / \mathrm{cm}^{2}\right)$ and cultured in DMEM-F12/Neurocult 1:1 supplemented with 1:200 $\mathrm{N}_{2}$ supplement, 1:100 B27 supplement lacking vitamin A, $3 \mu \mathrm{M}$ CHIR 99,021 (Sigma-Aldrich, Saint Louis, MO, USA), $0.5 \mu \mathrm{M}$ purmorphamine, $150 \mu \mathrm{M}$ ascorbic acid and $1 \%$ penicillin/streptomycin/glutamine in a humidified incubator set to $37^{\circ} \mathrm{C}$ and $5 \% \mathrm{CO}_{2}$. For neuronal differentiation, NPCs on ceramic substrates were cultured for 21-35 days in DMEM-F12/Neurocult 1:1 supplemented with 1:200 $\mathrm{N}_{2}$ supplement, 1:100 B27 supplement lacking vitamin A 8. All cell-culture media were changed every $48 \mathrm{~h}$.

\subsection{MTT Cell Viability Assay}

For the estimation of cell viability on calcined $\mathrm{Al}_{2} \mathrm{O}_{3}$ ceramic substrates, NPCs were incubated with $5 \mathrm{ug} / \mathrm{mL}$ MTT (Millipore) for $4 \mathrm{~h}$ at $37^{\circ} \mathrm{C}$ and $5 \% \mathrm{CO}_{2}$. Culture medium was removed and formazan crystals were solubilized with DMSO. OD 570/630 was measured in a BioTek ELX800 apparatus (BioTek, Winooski, VT, USA). 


\section{7. $R T-q P C R$}

Total RNA was purified from control or differentiated NPCs grown on ceramic substrates using the NucleoSpin RNA kit (Macherey-Nagel, Düren, Germany), according to manufacturer's instructions. cDNA generation and RT-qPCR reactions were performed using the KAPA SYBR FAST One-step Universal kit (KAPA Biosystems) in a Rotor-Gene 6000 operating system (Qiagen, Hilden, Germany). Primer sequences are shown in Table 2. The correct size of amplified RT-qPCR products was verified by electrophoresis in a $2 \%$ agarose gel.

Table 2. Sequences of primers used in RT-qPCR experiments.

\begin{tabular}{|c|c|c|}
\hline Target Gene & Forward Primer & Reverse Primer \\
\hline NeuN & 5'-CCAAGCGGCTACACGTCT-3' & 5'-GCTCGGTCAGCATCTGAG-3' \\
\hline TUBB3 & 5'-CCAAGGGTCACTACACGGAG-3' & 5'-ATGATGCGGTCGGGATACTC-3' \\
\hline S100B & 5'-ATGTCTGAGCTGGAGAAGG-3' & 5'-CTCATGTTCAAAGAACTCGTG-3' \\
\hline SYP & 5'-CTGTGACCTCGGGACTCAAC-3' & 5'-CATAGTCAGGCTGGTAGCCG-3' \\
\hline NLGN1 & 5'-CСТTTCCAGCTGGGCTGTTA-3' & 5'-TCTGGGGGTCGTCTGGTATT-3' \\
\hline GRIP1 & 5'-CCGTTGTCAAATTCTGAGGCG-3' & 5'-TACCGTCAGACCCAGGGTAG-3' \\
\hline
\end{tabular}

\subsection{Statistical Analysis}

Statistical analysis was performed using the GraphPad Prism software v.4 (San Diego, CA, USA). All experiments were performed in triplicates and results are shown as mean \pm SD calculated by a T-test.

\subsection{Scanning Electron Microscopy (SEM)}

NPCs on ceramic substrates were fixed with $4 \%$ glutaraldehyde for $30 \mathrm{~min}$ before dehydrated in increasing concentrations of ethanol. Samples were air dried, mounted on SEM stubs, using a two-sided adhesive film, and covered by a thin gold coating. Microscopic observation was carried out using a JSM-6300 JEOL SEM instrument (JEOL Ltd., Tokyo, Japan), operating at an accelerating voltage of $20 \mathrm{kV}$.

\section{Results}

\subsection{Substrate Characterization}

The properties of the substrate material, such as surface microstructure and chemical composition as well as mechanical properties, have a significant effect on the bioactivity of cells and the construction of building blocks for engineered biosystems [19,23]. Cell adhesion, survival, and proliferation on materials largely depends on surface characteristics such as wettability, chemistry, charge, rigidity, and roughness.

\subsubsection{Surface Topology and Nanoporosity}

Alumina samples (Table 3) were characterized via X-Ray diffraction spectroscopy for their crystal structure and by BET analysis for their surface area calculation and pore size distribution profile, where measurable. In the case of $\mathrm{cA}$, the surface area corresponded to a dense structure and could not be measured by the BET analysis. Figure 1 depicts the hexagonal crystal structure of $\alpha-\mathrm{Al}_{2} \mathrm{O}_{3}$ and a proposed mechanism for protein attachment on the surface hydroxyl groups that are formed when alumina exists in aquatic environments. FTIR spectroscopy performed on the cA and ncA samples (Supplementary Figure S1) validated the presence of characteristic surface hydroxyl groups on which proteins may attach. 
Table 3. Alumina Sample characteristics.

\begin{tabular}{cccc}
\hline Sample & Calcination Temperature $\left({ }^{\circ} \mathbf{C}\right)$ & Surface Area $\left(\mathbf{m}^{2} / \mathbf{g r}\right)$ & Crystallite Size $(\mathbf{n m})$ \\
\hline $\mathrm{ncA}$ & 800 & 5.56 & 42.28 \\
$\mathrm{cA}$ & 1650 & - & 42.29 \\
\hline
\end{tabular}

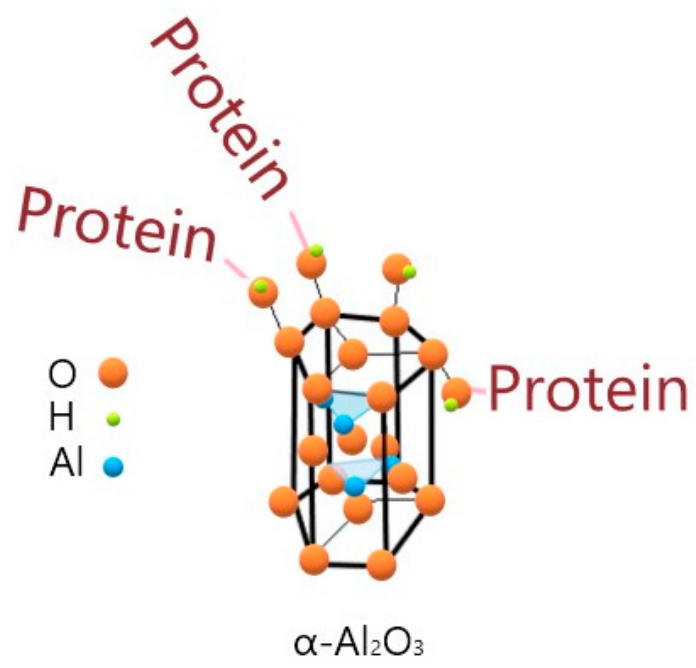

Figure 1. Hexagonal crystal structure of $\alpha-\mathrm{Al}_{2} \mathrm{O}_{3}$ and proposed protein attachment on surface hydroxyl $(-\mathrm{OH})$ bonds.

\section{XRD Spectroscopy}

Figure 2a depicts the XRD diagram of the cA sample, exhibiting the characteristic a- $\mathrm{Al}_{2} \mathrm{O}_{3}$ crystal structure, while a low intensity $\mathrm{SiO}_{2}$ peak appears only at the high temperature calcined cA sample at 26.7 $2 \theta$, possibly due to crystallization of small amount of $\mathrm{SiO}_{2}$ in the $\mathrm{Al}_{2} \mathrm{O}_{3}$ structure. The a- $\mathrm{Al}_{2} \mathrm{O}_{3}$ crystallite size, shown in Table 3, is calculated by applying the Debye-Scherrer formula on the Full Width at Half Maximum (FWHM) of the main peak at $43.42 \theta$ (Figure 2b).

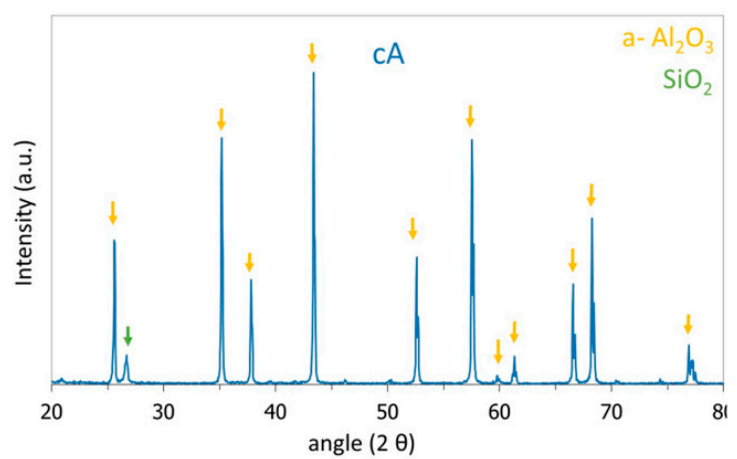

(a)

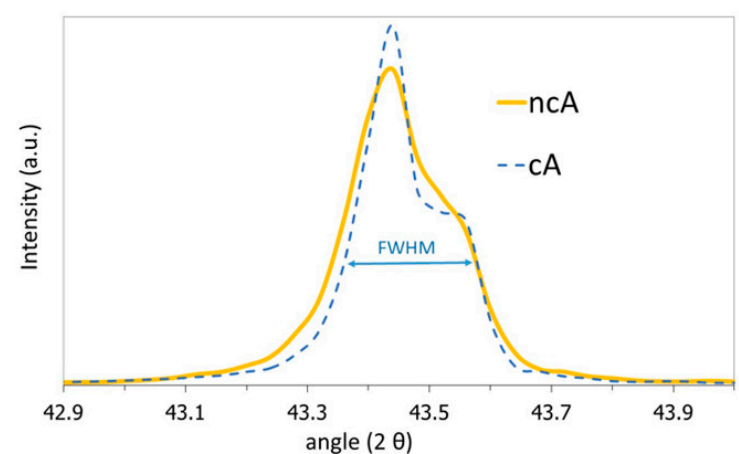

(b)

Figure 2. (a) XRD diagram of calcined (cA) sample depicting the a- $\mathrm{Al}_{2} \mathrm{O}_{3}$ crystal structure and (b) main a- $\mathrm{Al}_{2} \mathrm{O}_{3}$ peak at $43.42 \theta$ comparison for the two samples.

\section{BET Analysis}

BET analysis indicated a surface area of $5.32 \mathrm{~m}^{2} / \mathrm{gr}$ for the ncA sample, while no surface area could be measured for the $\mathrm{cA}$, as shown in Table 3. The extended calcination at high temperature $\left(1650^{\circ} \mathrm{C}\right)$ provoked sintering at the nano- and micropores of $\mathrm{cA}$, leading to a dense structure that did not exhibit any nitrogen adsorption and desorption hysteresis during BET analysis, thus the surface area of the sample was not measurable. The pore size distribution diagram for the ncA sample, derived 
from the nitrogen pressure values during the adsorption step, is shown in Figure 3, and depicts a pore distribution at $50-80 \mathrm{~nm}$. The high temperature calcination modified the porosity of the material by sintering the structure and blocking the original pore network.

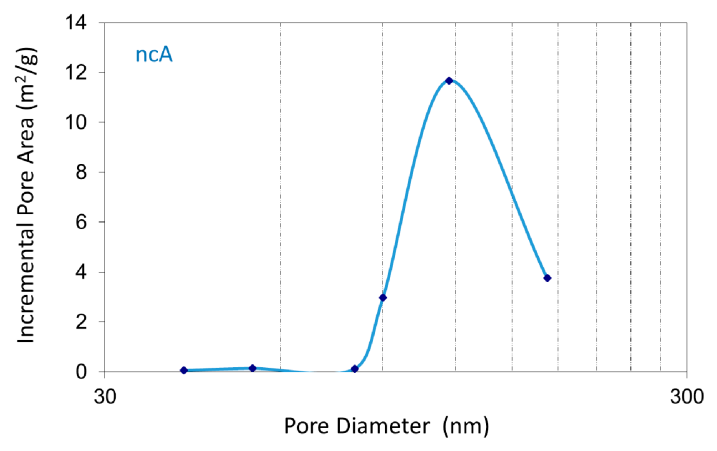

Figure 3. Pore size distribution of the non-calcined (ncA) sample.

\section{Scanning Electron Microscopy (SEM)}

The microstructural characteristics of the alumina surface may affect the attachment and survival of the cells. Therefore, the morphology of the sample was observed by SEM. The ncA sample at Figure 4 a consists of polycrystalline aggregates with a mean size of $400 \mathrm{~nm}$, which sinter with high temperature calcination to larger aggregates in the cA sample (Figure $4 \mathrm{~b}$ ) of 5-20 $\mu \mathrm{m}$ and forms a consistent flat surface.

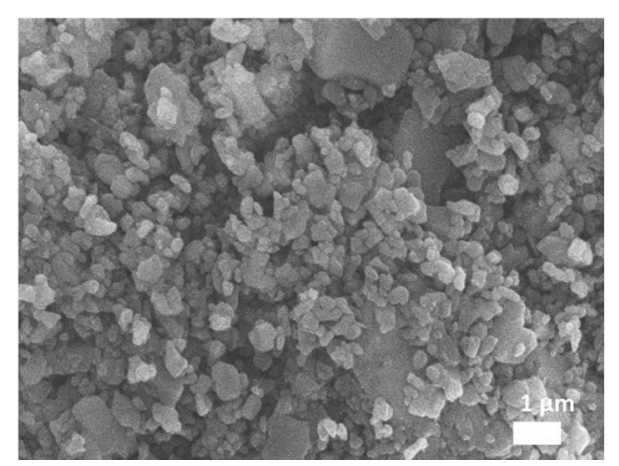

(a)

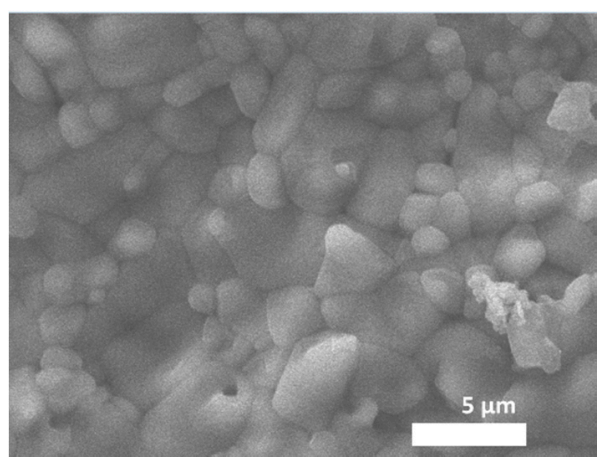

(b)

Figure 4. Scanning electron microscopy (SEM) images of (a) ncA and (b) cA samples.

\subsubsection{Wettability}

The wettability of the surfaces of non-calcined (ncA) and calcined alumina (cA) substrate was measured by the water contact angle. Values for non-calcined and calcined alumina substrate were $32.6^{\circ} \pm 4.05^{\circ}$ and $67.36^{\circ} \pm 4.77^{\circ}$, respectively, which indicates that they have a significantly different wettability (Figure 5), probably due to the elimination of the surface porosity by the calcination procedure. 


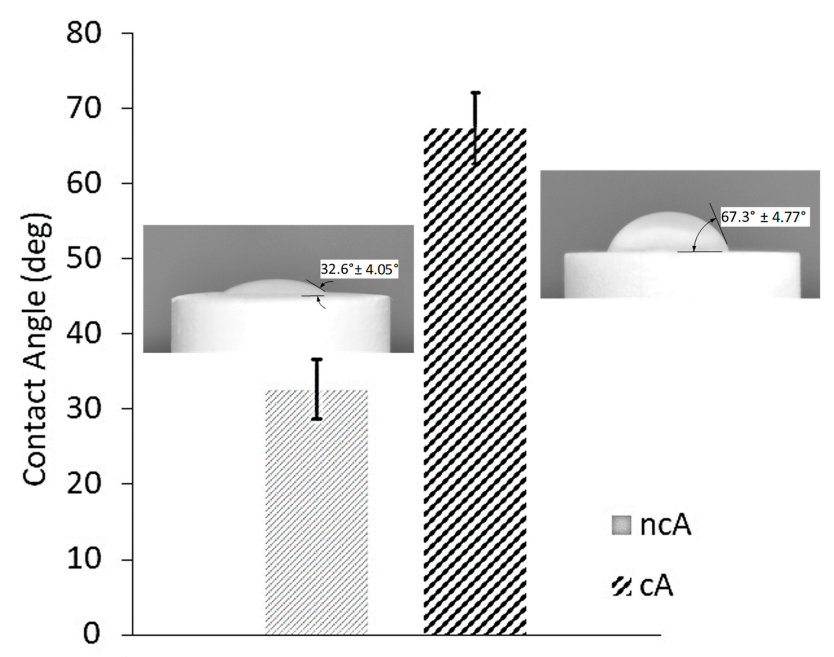

Figure 5. Contact angle values obtained from triplicate drops, highlighting the effect of calcination. Error bars denote \pm SD. Inserts are optical images showing contact angle values for $50 \mu \mathrm{L}$ of dDI water on non-calcined (ncA) or calcined (cA) a-alumina.

\subsection{Biological Assays}

\subsubsection{Biocompatibility of $\mathrm{Al}_{2} \mathrm{O}_{3}$ Ceramic Substrates with Human NPCs}

First, we assessed whether alumina substrates are compatible with human NPCs. Cells were seeded on various matrigel-coated discs, including calcined $\mathrm{Al}_{2} \mathrm{O}_{3}$ and viability was measured. Cells easily attached on most ceramic substrates but a higher viability was observed in $\mathrm{Al}_{2} \mathrm{O}_{3}$ and $\mathrm{ZrO}_{2}$ substrates (Supplementary Figure S2a,b). NPCs were further cultured on $\mathrm{Al}_{2} \mathrm{O}_{3}$ or $\mathrm{ZrO}_{2}$ discs in order to measure their relative proliferation. Cells on $\mathrm{Al}_{2} \mathrm{O}_{3}$ almost doubled in number within 6 days, as measured by MTT assay (Figure 6), similar to NPC proliferation on $\mathrm{ZrO}_{2}$, (Supplementary Figure S2c) which has been previously utilized for bone tissue engineering in combination with human stem cells $[24,25]$.

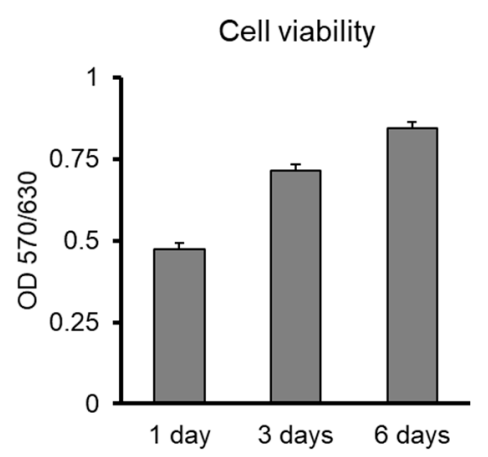

Figure 6. Biocompatibility of $\mathrm{Al}_{2} \mathrm{O}_{3}$ substrates with human NPCs-Viability of cells cultured on calcined matrigel-coated $\mathrm{Al}_{2} \mathrm{O}_{3}$ discs.

SEM indicated that cells formed a layer on the top of the disc covering the whole surface of the substrate (Figure 7a). Then, we asked whether NPCs grown on alumina discs retain their differentiation ability. To do so, cells were spontaneously differentiated towards mixed neuronal populations. As shown in Figure 7b, NPCs formed a neuronal network after three weeks of differentiation. Differentiated cells displayed a high degree of inter-connectivity, suggesting the formation of active synapses. 

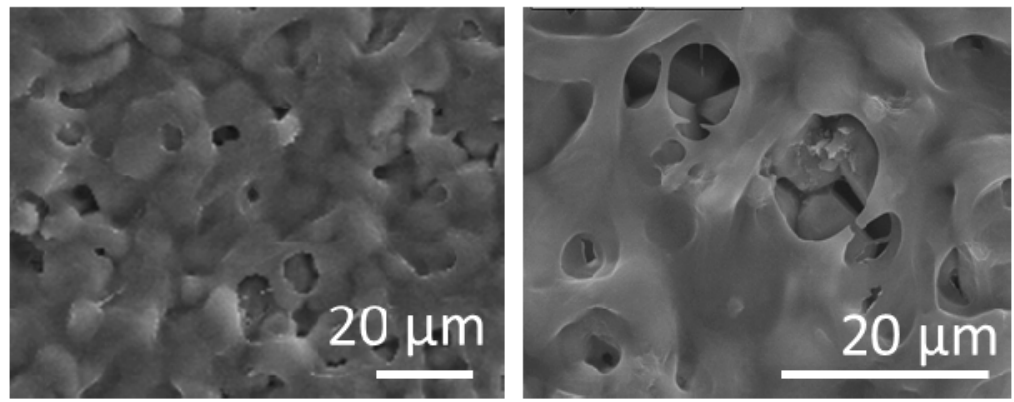

(a)
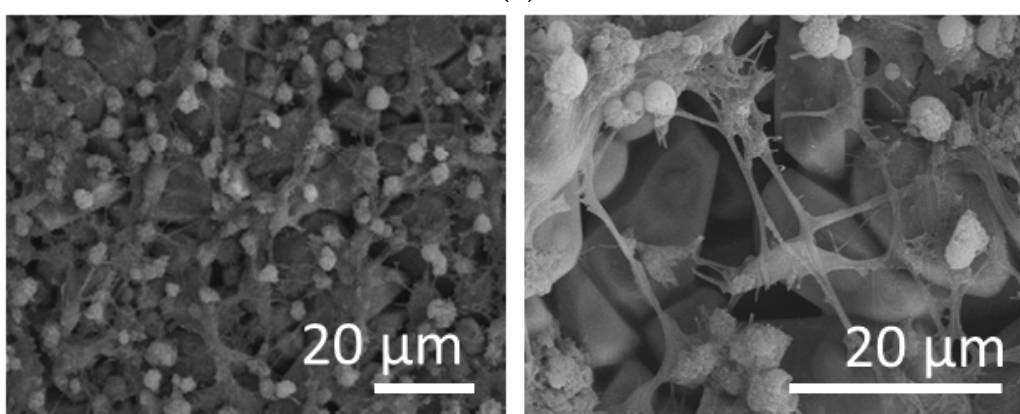

(b)

Figure 7. Biocompatibility of $\mathrm{Al}_{2} \mathrm{O}_{3}$ substrates with human NPCs-SEM images of (a) undifferentiated and $(\mathbf{b})$ differentiated NPCs (scale bar $=20 \mu \mathrm{m}$ ).

The efficiency of differentiation was determined by RT-qPCR. Differentiated NPCs expressed high levels of NeuN and TUBB3, two markers of mature neurons and S100B, a glial marker compared to undifferentiated NPCs (Figure 8). This indicates that the neuronal network formed on the top of $\mathrm{Al}_{2} \mathrm{O}_{3}$ discs contains mixed populations of viable neurons and glial cells.

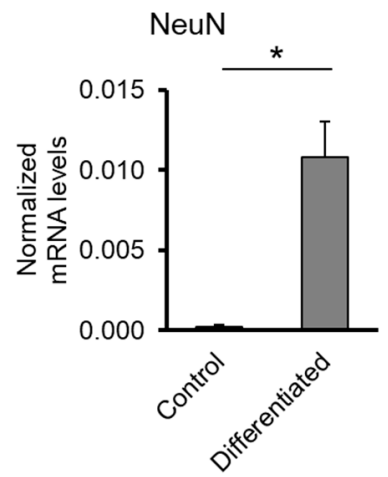

(a)

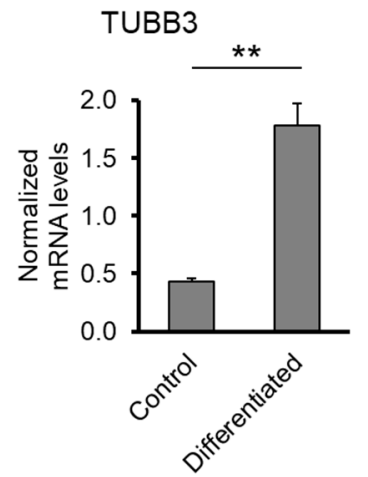

(b)

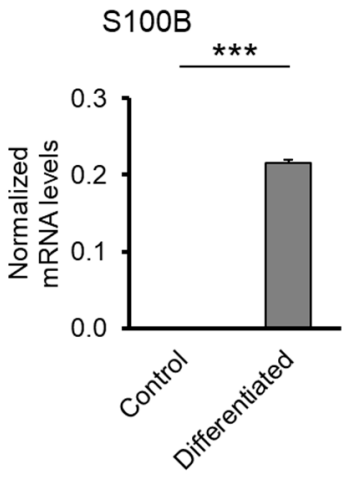

(c)

Figure 8. Biocompatibility of $\mathrm{Al}_{2} \mathrm{O}_{3}$ substrates with human NPCs-Expression levels of the neuronal markers (a) NeuN; (b) TUBB3; (c) S100B. Error bars denote \pm SD $\left({ }^{*} p\right.$-value $<0.05,{ }^{* *} p$-value $<0.01$, *** $p$-value $<0.001)$.

\subsubsection{Functionality of the Neuronal Network on $\mathrm{Al}_{2} \mathrm{O}_{3}$ Ceramic Substrates}

Next, we asked whether the neuronal network formed on $\mathrm{Al}_{2} \mathrm{O}_{3}$ discs is functional. Functionality of the network was indirectly assessed by expression of pre- and post-synaptic markers in differentiated NPCs, measurement of their long-term viability and observation of cellular morphology. Differentiated cells expressed high levels of synaptophysin (SYP), a pre-synaptic marker, neuroligin-1 (NLGN1), 
a post-synaptic marker regulating synaptic maturation and glutamate receptor-interacting protein 1 (GRIP1), a post-synaptic marker that binds to glutamate receptors (Figure 9).

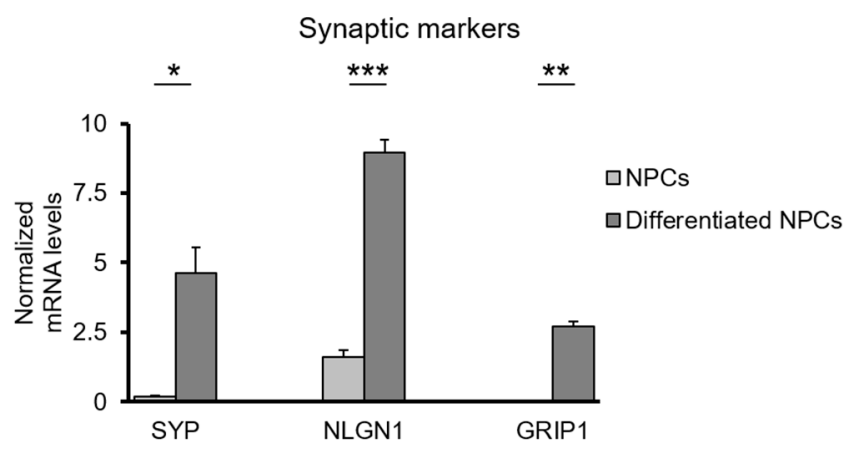

Figure 9. Functionality of NPC-derived neurons on $\mathrm{Al}_{2} \mathrm{O}_{3}$ substrates-Expression levels of synaptic markers in differentiated and undifferentiated NPCs. Error bars denote $\pm \mathrm{SD}(* p$-value $<0.05$, ${ }^{* *} p$-value $<0.01,{ }^{* * *} p$-value $\left.<0.001\right)$.

Functionality of neurons is directly related to their viability. Therefore, the viability of differentiated NPCs cultured on $\mathrm{Al}_{2} \mathrm{O}_{3}$ discs was estimated. Even though approximately $50 \%$ of cells died upon their differentiation and maturation (21 days), a significant number of differentiated NPCs were viable for up to 35 days (Figure 10). This suggests that they remain functional in long-term cultures.

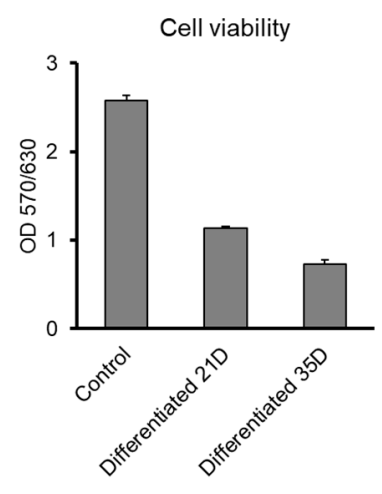

Figure 10. Functionality of NPC-derived neurons on $\mathrm{Al}_{2} \mathrm{O}_{3}$ substrates-Viability of differentiated cells in long-term cultures.

Furthermore, viable cells had short and long neuronal outgrowths (Figure 11) indicating the potential presence of both dendrites and neurites, as those detected in functional neurons. Collectively, these results indicate that the neuronal network formed on $\mathrm{Al}_{2} \mathrm{O}_{3}$ discs contains functional neurons that can efficiently transduce neuronal signals.

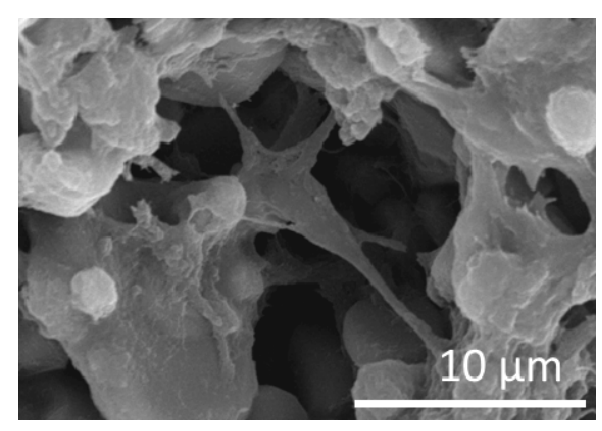

Figure 11. Functionality of NPC-derived neurons on $\mathrm{Al}_{2} \mathrm{O}_{3}$ substrates-SEM image of a viable neuron cultured for 35 days on matrigel-coated $\mathrm{Al}_{2} \mathrm{O}_{3}$ discs (scale bar $=10 \mu \mathrm{m}$ ). 


\section{Discussion}

$\mathrm{Al}_{2} \mathrm{O}_{3}$ exist in various structures which irreversibly transform into $\alpha$-alumina upon heat treatment at $1050-1200{ }^{\circ} \mathrm{C}$ [26]. $\alpha$-Alumina is thermodynamically the most stable phase and exhibits high elastic modulus (stiffness), hardness, and excellent resistance to the attack of strong inorganic acids (Table 1) [20], characteristics that have established alumina as a promising material both for tissue engineering implant and stem cell seeding scaffolds. Additionally, porous alumina due to its non-degrading characteristics has a variety of biological applications in vitro and in vivo, including immuno-isolation, biofiltration, or biosensing [27].

As a biomaterial, alumina has been applied in nanoparticle, coated particle, porous membrane and scaffold forms, addressing different biocompatibility issues related to the respective material structural and morphological characteristics [28,29]. cA sample is pristine alumina, exhibiting distinct narrow peaks attributed to the polycrystalline $\mathrm{a}-\mathrm{Al}_{2} \mathrm{O}_{3}$ structure, well known for its biocompatibility, which is also in consistency with the attachment and proliferation of the stem cells exhibited in Figures 6 and 7. The BET analysis in Table 3 showed that the cA sample has no porosity, in contrast to the $\mathrm{ncA}$, which had a pore size distribution in the range of 50-70 $\mathrm{nm}$. The morphology by SEM depicted that calcination resulted in the sintering of the ncA aggregates at the range of $\sim 1 \mu \mathrm{m}$ with irregular connectivity and produced larger aggregates of $\sim 5 \mu \mathrm{m}$ with coherent connection, restricting height irregularities at a flatter structure of Figure $4 \mathrm{~b}$ in contrast to that of Figure $4 \mathrm{a}$, which exhibited cavities in the $1 \mu \mathrm{m}$ range between the alumina aggregates.

The water contact angle in Figure 5 shows the wettability potential of the samples, denoting the increased wettability of the nCA due to the lower calcination exposure, which is in agreement with the BET analysis. When alumina—as a metal oxide MexOy—is exposed to water or humid air (15\% relative humidity), surface interactions with water can form hydroxyl $(-\mathrm{OH})$ groups. These groups facilitate the adsorption of proteins and increase its wettability [30], allowing the attachment and proliferation of cells.

In recent studies, there is evidence for the direct effect of pore size to cell viability, especially in alumina membranes with well-structured hexagonal pore network of $20 \mathrm{~nm}$ and $200 \mathrm{~nm}$. This shows that the $20 \mathrm{~nm}$ substrate induced lower degree of cell spreading and activation [31] while the $200 \mathrm{~nm}$ one showed homogeneous cell adhesion with lack of cell aggregation along the membrane surface. The controlled nano- and microporosity of alumina substrates that can be synthesized by various techniques such as anodic synthesis (PAA) or by slip casting [32,33] can be optimized for bioengineering applications with neuronal cells.

In our study, the homogeneous covering of cA substrates with matrigel in combination with the decreased porosity of the biomaterial promoted the efficient attachment, proliferation and differentiation of human NPCs. Matrigel coating, potentially mediated by the available hydroxyl groups on the surface of $\mathrm{cA}$, mimics the extracellular matrix; it also provides extrinsic signals which are necessary for the survival of neurons and regulate their functionality. Even though the neuronal network formed on cA substrates is functional for a significant period of time, further optimization of the culturing conditions is needed (e.g., by adding extra layers of supporting cells, such as astrocytes) in order to increase the viability of neurons and the long-term functionality of the network. Furthermore, the surface and morphological characteristics of the primary material can be modified to increase its biocompatibility as a scaffold for cell culture, reproducing desired 3D tissue architectures.

Organoids having a 3D spatial distribution of cells are considered developmental models of human organs at a miniature scale [34,35]. They are utilized for disease modeling and offer the possibility to replace animals for functional analysis or drug testing [36]. However, the technology for their generation requires further improvement as they are restricted to a small size and are characterized by significant cell death. Alternatively, organoids can be generated on scaffolds made by biocompatible materials, which can be afterwards seeded with cells. In combination with 3D printing, such scaffolds may be designed to contain channels which would efficiently supply the necessary nutrients to the inner layers of the organoid and increase cell viability (reviewed in [37]). In addition, by employing additive 
manufacturing methods, favorable properties of 3D sponge or foam porous scaffolds, commonly used in tissue engineering (e.g., bone regrowth, vascularization, and extracellular matrix deposition) can be acquired (e.g., interconnected pore structure for enhanced mechanical properties, uniform tissue development, and rapid mass transport kinetics) [38,39]. To this end, ceramics, including alumina, may provide permanent support compared to biodegradable materials whose degradation might affect cell viability and the 3D architecture of the organoid.

Even though ceramics may not be optimal biomaterials for regenerative medicine in soft tissues (e.g., brain), they have several advantages as they allow the spreading of cells, elongation of their axons, and formation of active synapses. Alumina is a cost-effective biomaterial and can be used for the construction of solid matrixes directing the growth of axons, potentially improving the integration of an implant into neural tissue [5]. Our work also indicates the potential use of alumina for the construction of neural organoids or engineered ex vivo biosystems (e.g., biosensors coated with neural stem cells). Alumina may be a valuable biomaterial for biomedical applications using human neurons. The envisaged application is the development of an organoid mimicking brain function, in which a sponge like structure will ensure the prerequisite properties with its optimized interconnected pore structure. As a next step of ours, additive manufacturing methods will be employed in order to attempt to build an organoid 3D structure based on alumina.

Supplementary Materials: The following are available online at http://www.mdpi.com/2079-4983/11/3/65/s1. Supplementary Figure S1. FTIR spectra of cA (blue color) and ncA (yellow color) depicting the characteristic peaks for hydroxyl groups. Supplementary Figure S2a,b. Representative image and quantification of the viability of NPCs seeded on various ceramic substrates. Blue color in (a) indicates insoluble formazan crystals formed by viable cells on the surface of each disc. (c) Viability of cells cultured for up to 6 days on matrigel-coated $\mathrm{ZrO}_{2}$ discs.

Author Contributions: Conceptualization and methodology, A.A. and S.P.; experimentation, A.A., I.G. and S.P.; resources, A.A., A.P., G.K. and V.T.Z.; data curation, A.A., I.G., G.K. and S.P.; writing-original draft preparation, A.A., G.K., S.P.; writing-review and editing, V.T.Z. All authors have read and agreed to the published version of the manuscript.

Funding: This research was funded by the Hellenic Foundation for Research and Innovation (HFRI) and the General Secretariat for Research and Technology (GSRT) of Greece [grant agreement No. 122 to SP]; the KRIPIS action, funded by GSRT and partially by the EPAnEK 2014-2020 Operational Programme (IMPACT project).

Acknowledgments: The authors wish to thank Anna Mavridou and Spyros Tsipidis for technical assistance.

Conflicts of Interest: The authors declare no conflict of interest.

\section{References}

1. Kato-Negishi, M.; Morimoto, Y.; Onoe, H.; Takeuchi, S. Millimeter-sized neural building blocks for 3D heterogeneous neural network assembly. Adv. Healthc. Mater. 2013, 2, 1564-1570. [CrossRef] [PubMed]

2. Zhuang, P.; Sun, A.X.; An, J.; Chua, C.K.; Chew, S.Y. 3D neural tissue models: From spheroids to bioprinting. Biomaterials 2018, 154, 113-133. [CrossRef]

3. Fuhrer, E.; Backer, A.; Kraft, S.; Gruhl, F.J.; Kirsch, M.; MacKinnon, N.; Korvink, J.G.; Sharma, S. 3D Carbon scaffolds for neural stem cell culture and magnetic resonance imaging. Adv. Healthc. Mater. 2018, 7. [CrossRef]

4. Guo, W.; Qiu, J.; Liu, J.; Liu, H. Graphene microfiber as a scaffold for regulation of neural stem cells differentiation. Sci. Rep. 2017, 7, 5678. [CrossRef] [PubMed]

5. Mou, X.; Wang, S.; Guo, W.; Ji, S.; Qiu, J.; Li, D.; Zhang, X.; Zhou, J.; Tang, W.; Wang, C.; et al. Localized committed differentiation of neural stem cells based on the topographical regulation effects of TiO2 nanostructured ceramics. Nanoscale 2016, 8, 13186-13191. [CrossRef]

6. Patel, B.B.; Sharifi, F.; Stroud, D.P.; Montazami, R.; Hashemi, N.N.; Sakaguchi, D.S. 3D Microfibrous scaffolds selectively promotes proliferation and glial differentiation of adult neural stem cells: A platform to tune cellular behavior in neural tissue engineering. Macromol. Biosci. 2019, 19, e1800236. [CrossRef]

7. Wang, S.; Guan, S.; Xu, J.; Li, W.; Ge, D.; Sun, C.; Liu, T.; Ma, X. Neural stem cell proliferation and differentiation in the conductive PEDOT-HA/Cs/Gel scaffold for neural tissue engineering. Biomater. Sci. 2017, 5, 2024-2034. [CrossRef] [PubMed] 
8. Kourgiantaki, A.; Tzeranis, D.S.; Karali, K.; Georgelou, K.; Bampoula, E.; Psilodimitrakopoulos, S.; Yannas, I.V.; Stratakis, E.; Sidiropoulou, K.; Charalampopoulos, I.; et al. Neural stem cell delivery via porous collagen scaffolds promotes neuronal differentiation and locomotion recovery in spinal cord injury. NPJ Regen. Med. 2020, 5, 12. [CrossRef] [PubMed]

9. Ma, Q.; Yang, L.; Jiang, Z.; Song, Q.; Xiao, M.; Zhang, D.; Ma, X.; Wen, T.; Cheng, G. Three-dimensional stiff graphene scaffold on neural stem cells behavior. ACS Appl. Mater. Interfaces 2016, 8, 34227-34233. [CrossRef]

10. Tang-Schomer, M.D.; White, J.D.; Tien, L.W.; Schmitt, L.I.; Valentin, T.M.; Graziano, D.J.; Hopkins, A.M.; Omenetto, F.G.; Haydon, P.G.; Kaplan, D.L. Bioengineered functional brain-like cortical tissue. Proc. Natl. Acad. Sci. USA 2014, 111, 13811-13816. [CrossRef]

11. Boccaccini, A.R.; Blaker, J.J. Bioactive composite materials for tissue engineering scaffolds. Expert Rev. Med. Devices 2005, 2, 303-317. [CrossRef]

12. Jones, J.R. Review of bioactive glass: From hench to hybrids. Acta Biomater. 2013, 9, 4457-4486. [CrossRef]

13. Baino, F.; Novajra, G.; Vitale-Brovarone, C. Bioceramics and Scaffolds: A winning combination for tissue engineering. Front. Bioeng. Biotechnol. 2015, 3, 202. [CrossRef]

14. Rahmati, M.; Mozafari, M. Biocompatibility of alumina-based biomaterials-A review. J. Cell. Physiol. 2019, 234, 3321-3335. [CrossRef]

15. Swan, E.E.; Popat, K.C.; Desai, T.A. Peptide-immobilized nanoporous alumina membranes for enhanced osteoblast adhesion. Biomaterials 2005, 26, 1969-1976. [CrossRef]

16. Adiga, S.P.; Jin, C.; Curtiss, L.A.; Monteiro-Riviere, N.A.; Narayan, R.J. Nanoporous membranes for medical and biological applications. WIREs Nanomed. Nanobiotechnol. 2009, 1, 568-581. [CrossRef]

17. Gultepe, E.; Nagesha, D.; Sridhar, S.; Amiji, M. Nanoporous inorganic membranes or coatings for sustained drug delivery in implantable devices. Adv. Drug Deliv. Rev. 2010, 62, 305-315. [CrossRef]

18. Santos, A.; Sinn Aw, M.; Bariana, M.; Kumeria, T.; Wang, Y.; Losic, D. Drug-releasing implants: Current progress, challenges and perspectives. J. Mater. Chem. B 2014, 2, 6157-6182. [CrossRef]

19. Kuhn, P.T. The Effect of Wettability and Stiffness on Stem Cell Behavior at Biointerfaces. Ph.D. Thesis, Rijksuniversiteit Groningen, Groningen, The Netherlands, 2016.

20. THERMANSYS. T-Ceramics. Available online: https:/www.thermansys.com/gallery/files/Brochures/ Machinable_Ceramics/t-ceramics-machinables-January-2017.pdf (accessed on 5 May 2020).

21. Chen, H.; Muros-Cobos, J.L.; Amirfazli, A. Contact angle measurement with a smartphone. Rev. Sci. Instrum. 2018, 89, 035117. [CrossRef]

22. Lorenz, C.; Lesimple, P.; Bukowiecki, R.; Zink, A.; Inak, G.; Mlody, B.; Singh, M.; Semtner, M.; Mah, N.; Aure, K.; et al. Human iPSC-Derived neural progenitors are an effective drug discovery model for neurological mtDNA Disorders. Cell Stem Cell 2017, 20, 659-674. [CrossRef]

23. Yao, X.; Peng, R.; Ding, J. Cell-material interactions revealed via material techniques of surface patterning. Adv. Mater. 2013, 25, 5257-5286. [CrossRef]

24. Alizadeh, A.; Moztarzadeh, F.; Ostad, S.N.; Azami, M.; Geramizadeh, B.; Hatam, G.; Bizari, D.; Tavangar, S.M.; Vasei, M.; Ai, J. Synthesis of calcium phosphate-zirconia scaffold and human endometrial adult stem cells for bone tissue engineering. Artif. Cells Nanomed. Biotechnol. 2016, 44, 66-73. [CrossRef]

25. An, S.H.; Matsumoto, T.; Miyajima, H.; Nakahira, A.; Kim, K.H.; Imazato, S. Porous zirconia/hydroxyapatite scaffolds for bone reconstruction. Dent. Mater. 2012, 28, 1221-1231. [CrossRef]

26. Piconi, C.; Condo, S.G.; Kosmač, T. Alumina- and zirconia-based ceramics for load-bearing applications. In Advanced Ceramics for Dentistry; Shen, J.Z., Kosmač, T., Eds.; Butterworth-Heinemann: Oxford, UK, 2014; pp. 219-253.

27. Xifre-Perez, E.; Ferre-Borull, J.; Pallares, J.; Marsal, L.F. Mesoporous alumina as a biomaterial for biomedical applications. Open Mater. Sci. 2015, 2, 13-32. [CrossRef]

28. Catelas, I.; Petit, A.; Zukor, D.J.; Marchand, R.; Yahia, L.; Huk, O.L. Induction of macrophage apoptosis by ceramic and polyethylene particles in vitro. Biomaterials 1999, 20, 625-630. [CrossRef]

29. Takami, Y.; Yamane, S.; Makinouchi, K.; Otsuka, G.; Glueck, J.; Benkowski, R.; Nose, Y. Protein adsorption onto ceramic surfaces. J. Biomed. Mater. Res. 1998, 40, 24-30. [CrossRef]

30. Morterra, C.; Magnacca, G. A case study: Surface chemistry and surface structure of catalytic aluminas, as studied by vibrational spectroscopy of adsorbed species. Catal. Today 1996, 27, 497-532. [CrossRef]

31. Ferraz, N.; Hong, J.; Santin, M.; Karlsson Ott, M. Nanoporosity of alumina surfaces induces different patterns of activation in adhering monocytes/macrophages. Int. J. Biomater. 2010, 2010, 402715. [CrossRef] 
32. Koutsonikolas, D.E.; Kaldis, S.P.; Sklari, S.D.; Pantoleontos, G.; Zaspalis, V.T.; Sakellaropoulos, G.P. Preparation of highly selective silica membranes on defect-free $\gamma-\mathrm{Al}_{2} \mathrm{O}_{3}$ membranes using a low temperature CVI technique. Microporous Mesoporous Mater. 2010, 132, 276-281. [CrossRef]

33. Sklari, S.; Pagana, A.; Nalbandian, L.; Zaspalis, V.T. Ceramic membrane materials and process for the removal of As(III)/As(V) ions from water. J. Water Process Eng. 2015, 5, 42-47. [CrossRef]

34. Gupta, A.K.; Coburn, J.M.; Davis-Knowlton, J.; Kimmerling, E.; Kaplan, D.L.; Oxburgh, L. Scaffolding kidney organoids on silk. J. Tissue Eng. Regen. Med. 2019, 13, 812-822. [CrossRef] [PubMed]

35. Lancaster, M.A.; Renner, M.; Martin, C.A.; Wenzel, D.; Bicknell, L.S.; Hurles, M.E.; Homfray, T.; Penninger, J.M.; Jackson, A.P.; Knoblich, J.A. Cerebral organoids model human brain development and microcephaly. Nature 2013, 501, 373-379. [CrossRef]

36. Lancaster, M.A.; Knoblich, J.A. Organogenesis in a dish: Modeling development and disease using organoid technologies. Science 2014, 345, 1247125. [CrossRef]

37. Antill-O'Brien, N.; Bourke, J.; O'Connell, C.D. Layer-By-Layer: The Case for 3D bioprinting neurons to create patient-specific epilepsy models. Materials 2019, 12, 3218. [CrossRef]

38. Luo, Y. Three-dimensional scaffolds. In Principles of Tissue Engineering, 5th ed.; Lanza, R., Langer, R., Vacanti, J.P., Atala, A., Eds.; Academic Press: Cambridge, MA, USA, 2020. [CrossRef]

39. Nikolova, M.P.; Chavali, M.S. Recent advances in biomaterials for 3D scaffolds: A review. Bioact. Mater. 2019, 4, 271-292. [CrossRef]

(C) 2020 by the authors. Licensee MDPI, Basel, Switzerland. This article is an open access article distributed under the terms and conditions of the Creative Commons Attribution (CC BY) license (http://creativecommons.org/licenses/by/4.0/). 